\title{
Study on Shelling Techniques of Sweet Corn
}

\author{
S.B. Patil, J.S. Ghatge* and P.R. Sable \\ Dr. D. Y. Patil College of Agriculture Engineering and Technology, Talsande Dist., \\ Kolhapur, India
}

\begin{tabular}{|c|}
\hline \\
\hline $\begin{array}{l}\text { Sweet corn, Shelling, } \\
\text { Corn shelling rate and } \\
\text { corn shelling capacity }\end{array}$ \\
\hline Article Info \\
\hline $\begin{array}{l}\text { Accepted: } \\
\text { 07 March } 2018 \\
\text { Available Online: } \\
10 \text { April } 2018\end{array}$ \\
\hline
\end{tabular}

A B S T R A C T

The hand shelling using fingers remains the most favoured method for shelling of sweet corn cob kernels. The rate of hand shelling method is too low and also causes pain in the fingers used for plucking of the sweet corn kernel from the cob. It was observed in many cases the sweet corn kernels can be shelled by different techniques viz. shelling whole cob, shelling cob by breaking the cob across the length and shelling cob by splitting/paring the cob along the length. Therefore it was found necessary to study the shelling rate by these techniques. The three different sweet corn shelling techniques viz. Shelling whole cob (T1), shelling cob by breaking the cob across the length (T2) and shelling cob by splitting/paring the cob along the length (T3) were studied at Department of FMPE, Dr. D. Y. Patil College of Agricultural Engineering and Technology, Talsande Dist: Kolhapur in the Sept. 2017. A sweet corn cobs of Sugar-75 variety were used for the entire study. Corn shelling rate, Corn shelling capacity was studied. The average shelling rate (cobs/h) with technique T3 $(51.14 \mathrm{cobs} / \mathrm{h})$ was 5.17 and 3.6 times more than technique T1 and T2 respectively. The average shelling capacity $(\mathrm{kg} / \mathrm{h})$ with technique T3 $(13.58 \mathrm{~kg} / \mathrm{h})$ was 5.16 and 3.6 times more than technique $\mathrm{T} 1$ and $\mathrm{T} 2$ respectively.

\section{Introduction}

Sweet corn shelling for domestic consumption or for sale as frozen corns, is very critical and time consuming operations. The hand shelling is one of the preferred methods for shelling of sweet corn kernels. In few of the cases the use of a knife or spoon handle for shelling of sweet corn kernels but the percentage of broken kernels is far beyond the acceptance level hence, the hand shelling with fingers remains the most favoured method for it. The rate of hand shelling method is too low and also causes pain in the fingers used for plucking of the sweet corn kernel from the cob. It was observed in many cases the sweet corn kernels can be shelled by different techniques viz. shelling whole cob, shelling cob by breaking the cob across the length and shelling cob by splitting/paring the cob along the length. Therefore it was found necessary to study the shelling rate and shelling capacity of these techniques.

\section{Materials and Methods}

\section{Measurement of dimensions of sweet corn cobs}

The sweet corn cobs were dehusked and dimensions of dehusked sweet corn cobs were recorded before using for determination of 
shelling rate, shelling capacity as well as splitting/paring rate as follows

\section{Sweet corn cob length}

The height of seedlings was measured by using a $30 \mathrm{~cm}$ scale. For measurement purpose, the dehusked sweet corn cobs were selected randomly and 10 observations were noted in each case to find the average.

\section{Sweet corn cob stem diameter}

Seedling stem diameter of uprooted seedlings of different ages was measured with the help of vernier calliper. Ten observations were recorded in each case to take the mean.

Seedling stem diameter was measured at a distance of $25 \mathrm{~mm}$ from the bottom end to maintain uniformity.

\section{Techniques of hand shelling}

Three different techniques for the hand shelling of sweet corn cob viz. Shelling whole cob (T1), shelling cob by breaking the cob across the length (T2) and shelling cob by splitting/paring the cob along the length (T3) were studied to identify the advantages and limitations of the different techniques.

In whole cob shelling technique (T1), the cob was broken across the length and shelling was done lengthwise by using fingers as shown in Figure 1a. In case of shelling the sweet corn cob by breaking it across the length (T2), the cob was broken across the length as in case of $\mathrm{T} 1$ and shelling was done by fingers by detaching the lines of kernels on the circumference of the cob as shown in Figure 1b. Whereas, in case of shelling cob by splitting/paring the cob along the length (T3), The whole sweet corn cob was splitted/parred using the screw driver and the shelling was done lengthwise by using fingers as shown in
Figure 1c.

\section{Measurement of performance parameters}

The performance of different techniques for the hand shelling of sweet corn cob was carried out in the Department of Farm Machinery and Power Engineering, D. Y. Patil College of Agricultural Engineering and Technology, Talsande Dist: Kolhapur in Sept 2017. The sweet corn cobs of Sugar-75 variety with average length of $193 \mathrm{~mm}$ and $50.9 \mathrm{~mm}$ average diameter were used for the study. The physical properties of the sweet corn cobs selected for the study are given in Table 1 .

\section{Corn shelling rate}

The time required for 50 sweet corn cobs to shell completely with the three different sweet corn shelling techniques viz. Shelling whole cob(T1), shelling cob by breaking the cob across the length (T2) and shelling cob by splitting/paring the cob along the length (T3) was noted and the shelling rate was calculated by following formula,

Corn shelling rate (cobs/hr) = Number of sweet corn cobs shelled

Time, min

\section{Corn shelling capacity}

The weight of shelled sweet corn kernels in unit time is taken as corn shelling capacity. It was calculated for all the three different sweet corn shelling techniques viz. Shelling whole cob (T1), shelling cob by breaking the cob across the length (T2) and shelling cob by splitting/paring the cob along the length (T3) was noted and the corn shelling capacity was calculated by following formula

Corn shelling capacity $(\mathrm{kg} / \mathrm{hr})=$ Quantity of shelled sweet corn kernels, Kg

Time, min 
Table.1 Physical properties of the sweet corn cobs selected for the study

\begin{tabular}{|c|c|c|c|c|c|}
\hline Cob No. & $\begin{array}{c}\text { Length, } \\
\text { mm }\end{array}$ & $\begin{array}{c}\text { Diameter, } \\
\text { mm }\end{array}$ & $\begin{array}{c}\text { Weight of } \\
\text { cob with } \\
\text { kernels, gm }\end{array}$ & $\begin{array}{c}\text { Weight of } \\
\text { kernels, gm }\end{array}$ & $\begin{array}{c}\text { Weight of } \\
\text { shelled cob, } \\
\text { gm }\end{array}$ \\
\hline $\mathbf{1}$ & 200 & 50 & 380 & 294 & 86 \\
\hline $\mathbf{2}$ & 192 & 50 & 324 & 255 & 69 \\
\hline $\mathbf{3}$ & 200 & 51 & 375 & 175 & 70 \\
\hline $\mathbf{4}$ & 185 & 50 & 292 & 231 & 61 \\
\hline $\mathbf{5}$ & 210 & 55 & 416 & 275 & 66 \\
\hline $\mathbf{6}$ & 193 & 49 & 317 & 250 & 67 \\
\hline $\mathbf{7}$ & 187 & 49 & 278 & 255 & 23 \\
\hline $\mathbf{8}$ & 185 & 50 & 301 & 243 & 58 \\
\hline $\mathbf{9}$ & 204 & 51 & 371 & 288 & 83 \\
\hline $\mathbf{1 0}$ & 198 & 52 & 381 & 282 & 99 \\
\hline A verage & $\mathbf{1 9 5 . 4}$ & $\mathbf{5 0 . 7}$ & $\mathbf{3 3 3 . 7}$ & $\mathbf{2 6 5 . 5}$ & $\mathbf{6 8 . 2}$ \\
\hline
\end{tabular}

Table.2 Observations of different techniques of sweet corn shelling

\begin{tabular}{|c|c|c|c|c|c|c|}
\hline \multirow[t]{2}{*}{ Test } & \multicolumn{3}{|c|}{$\begin{array}{l}\text { Time require to shell } 25 \text { dehusked sweet } \\
\text { corn cobs }\end{array}$} & \multicolumn{3}{|c|}{ Shelling rate, cobs/hr } \\
\hline & T1 & $\mathbf{T} 2$ & T3 & T1 & T2 & T3 \\
\hline $\mathbf{I}$ & 8940 & 6015 & 1780 & 10.07 & 14.96 & 50.56 \\
\hline II & 9550 & 6445 & 1790 & 9.42 & 13.96 & 50.28 \\
\hline III & 8805 & 6530 & 1710 & 10.22 & 13.78 & 52.63 \\
\hline Avg & 9098.3 & 6330.0 & 1760.00 & 9.89 & 14.22 & 51.14 \\
\hline
\end{tabular}

T1- Shelling whole cob, T2- Shelling by breaking across the length and T3- Shelling by spliting/paring along the length

Table.3 Observations of different techniques of sweet corn shelling

\begin{tabular}{|c|c|c|c|c|c|c|}
\hline \multirow[t]{2}{*}{ Test } & \multicolumn{3}{|c|}{$\begin{array}{l}\text { Time require to shell } 25 \text { dehusked sweet } \\
\text { corn cobs, sec }\end{array}$} & \multicolumn{3}{|c|}{ Shelling capacity, kg/hr } \\
\hline & T1 & T2 & T3 & T1 & T2 & T3 \\
\hline I & 8940 & 6015 & 1780 & 2.67 & 3.97 & 13.42 \\
\hline II & 9550 & 6445 & 1790 & 2.50 & 3.71 & 13.35 \\
\hline III & 8805 & 6530 & 1710 & 2.71 & 3.66 & 13.97 \\
\hline$\overline{\text { Avg }}$ & 9098.3 & 6330.0 & 1760.00 & 2.63 & 3.78 & 13.58 \\
\hline
\end{tabular}

T1- Shelling whole cob, T2- Shelling by breaking across the length and T3- Shelling by spliting/paring along the length 


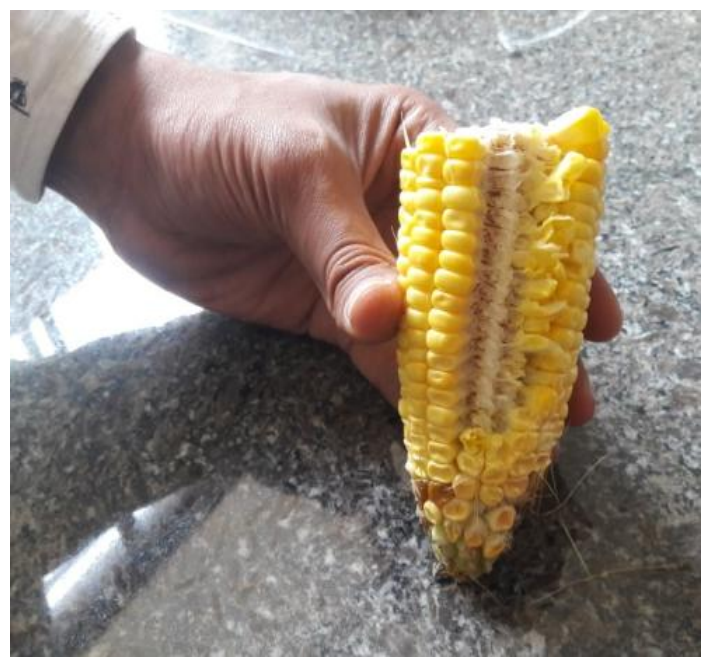

a) Shelling whole cob (T1)

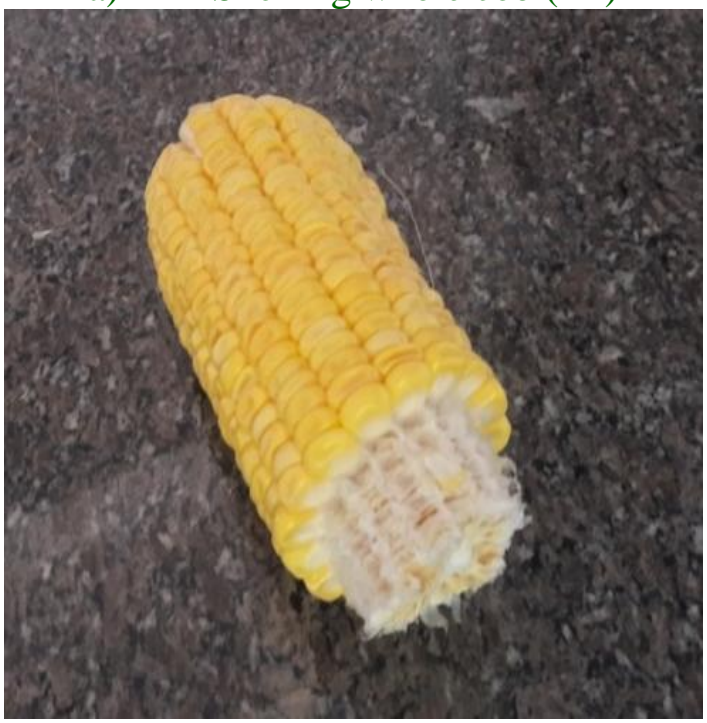

b) Shelling cob by breaking the cob across the length (T2)

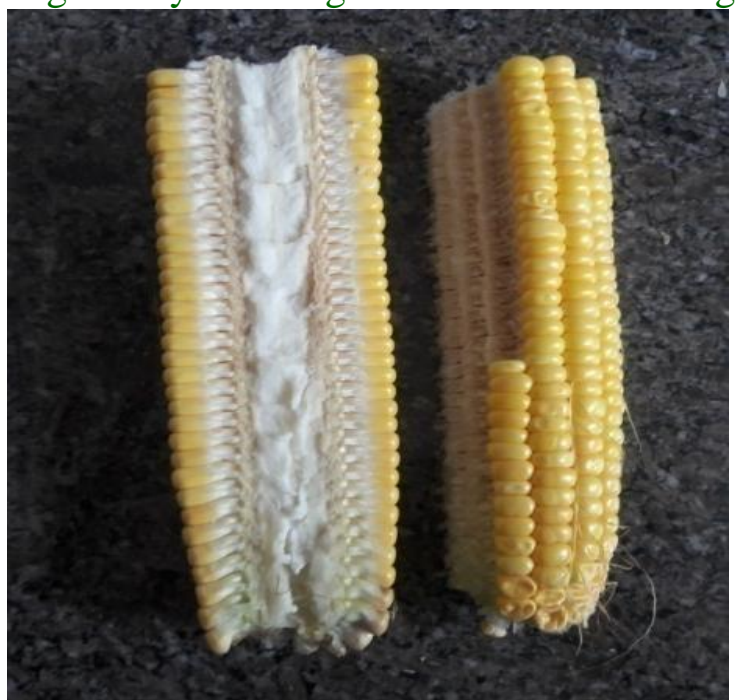

c) Splitting/paring the cob along the length (T3)

Fig.1 Different techniques for the hand shelling of sweet corn cob 
Fig.2 Shelling rate of different techniques of sweet corn shelling

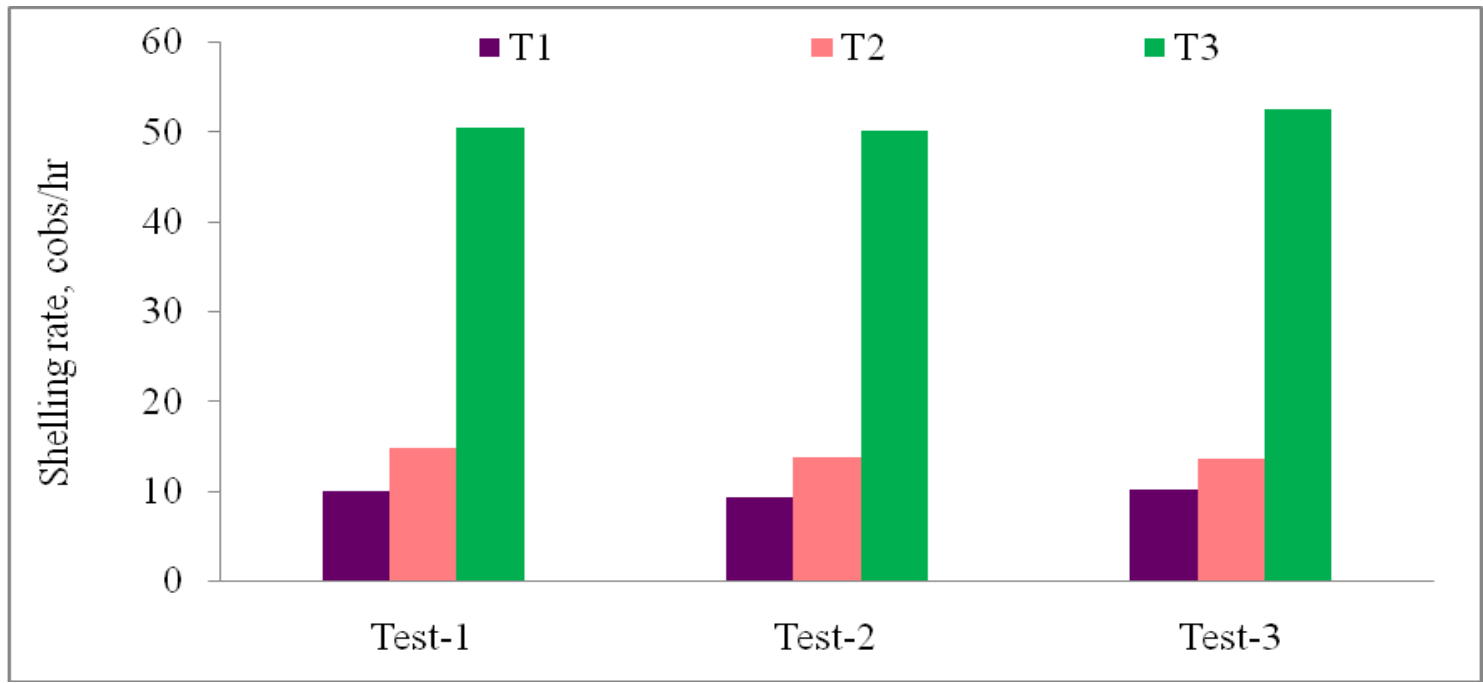

Fig.3 Shelling capacity of different techniques of sweet corn shelling

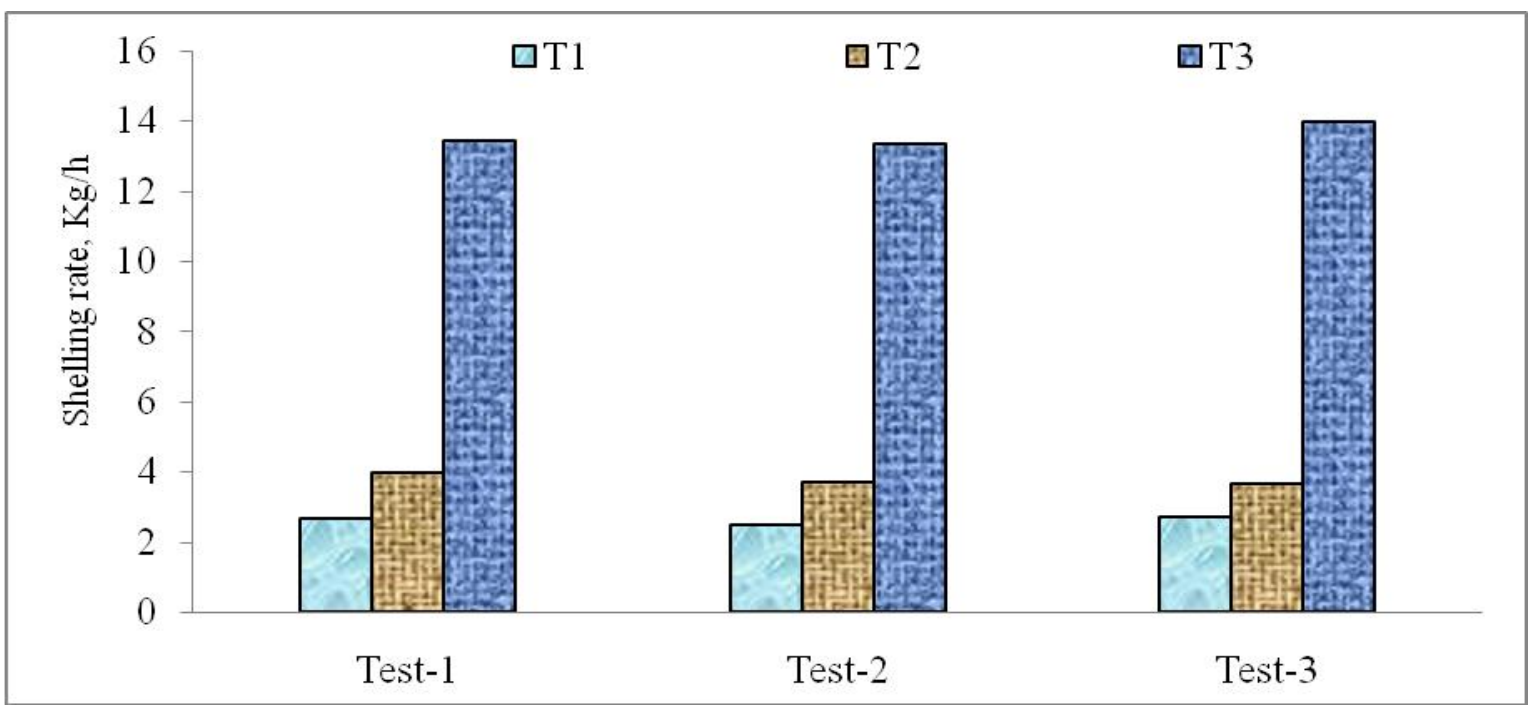

\section{Sweet corn cob splitting/paring rate}

The time required for 25 sweet corn cobs to split/par by manual method using screw driver and by using sweet corn cob splitting/parring machine was noted and the sweet corn cob splitting/paring rate was calculated by following formula,

Sweet corn cob splitting/paring rate (cobs/hr) Number of cobs splited/pared

$=\quad$ Time ${ }_{s}$ min

\section{Results and Discussion}

\section{Corn shelling rate}

The average values of corn shelling rate obtained with the three different sweet corn shelling techniques are presented in Table 2. The comparative corn shelling rate obtained with the three different sweet corn shelling techniques is presented by Figure 2. It can be seen from the Table 2 and Figure 2 that the highest corn shelling rate calculated as 
number of cobs/h was obtained with treatment T3 followed by T2 and T1.

The average shelling rate (cobs/h) with technique T3 was 5.17 and 3.6 times more than technique $\mathrm{T} 1$ and $\mathrm{T} 2$ respectively. The highest shelling rate in case of technique $\mathrm{T} 3$ was mainly due to the small size of cob which offered grip in holding the splitted/pared cob and ease of shelling of kernels from either side rows of kernels.

\section{Corn shelling capacity}

The average values of corn shelling capacity obtained with the three different sweet corn shelling techniques are presented in Table 3. The comparative corn shelling capacity obtained with the three different sweet corn shelling techniques is presented by Figure 3. It can be seen from the Table 3 and Figure 3 that the highest corn shelling capacity calculated as number of $\mathrm{kg} / \mathrm{h}$ was obtained with treatment $\mathrm{T} 3$ followed by $\mathrm{T} 2$ and $\mathrm{T} 1$.

The average shelling capacity $(\mathrm{kg} / \mathrm{h})$ with technique T3 was 5.16 and 3.6 times more than technique $\mathrm{T} 1$ and $\mathrm{T} 2$ respectively. The highest shelling capacity in case of technique T3 was mainly due to the small size of cob which offered grip in holding the splitted/pared cob and ease of shelling of kernels from either side rows of kernels.
The average shelling rate $(\mathrm{cobs} / \mathrm{h})$ with technique T3 $(51.14 \mathrm{cobs} / \mathrm{h})$ was 5.17 and 3.6 times more than technique $\mathrm{T} 1$ and $\mathrm{T} 2$ respectively. The average shelling capacity $(\mathrm{kg} / \mathrm{h})$ with technique T3 $(13.58 \mathrm{~kg} / \mathrm{h})$ was 5.16 and 3.6 times more than technique $\mathrm{T} 1$ and $\mathrm{T} 2$ respectively.

\section{References}

Ilori, T. A., Raji A. O and O. Kilanko (2013) Modelling some ergonomic parameters with machine parameter using hand powered Corn Sheller. Journal of Engineering and Technology Research, Vol. 5(3), pp. 52-57

Kinjara Bharata, (1988) Testing and evaluation of locally-maize sheller. $J$. Natl. Res. Council Thailand, 20 (2).

Kumar, B. A. and Shaik H. B. (2014) Design, development and performance evaluation of a hand operated Maize Sheller. International Journal of Agricultural Engineering, Vol. 7(1).

Mahatale, Y. V. and V. P. Pathak (2012) Physiological Evaluation of Different Manually Operated Corn Shelling Methods. International journal of Applied Agricultural Research. Vol. 7(3): 203-207

Nakakini, S.O. (2007) Manually Powered continuous flow maize sheller. Applied Energy 84, 1175-1186

\section{How to cite this article:}

Patil, S.B., J.S. Ghatge and Sable, P.R. 2018. Study on Shelling Techniques of Sweet Corn. Int.J.Curr.Microbiol.App.Sci. 7(04): 534-539. doi: https://doi.org/10.20546/ijcmas.2018.704.062 